\title{
Altered expression of mitochondrial and extracellular matrix genes in the heart of human fetuses with chromosome 2 I trisomy Anna Conti ${ }^{\dagger 1}$, Floriana Fabbrini ${ }^{\dagger 1,2}$, Paola D'Agostino ${ }^{2}$, Rosa Negri ${ }^{1}$, Dario Greco $^{3}$, Rita Genesio ${ }^{1,2}$, Maria D'Armiento ${ }^{4}$, Carlo Olla ${ }^{4}$ Dario Paladini ${ }^{5}$, Mariastella Zannini ${ }^{6}$ and Lucio Nitsch ${ }^{* 1,2}$
}

Address: ${ }^{1}$ Dipartimento di Biologia e Patologia Cellulare e Molecolare, University Federico II, Napoli, Italy, ${ }^{2}$ BIOGEM, Biotechnology and Molecular Genetics, Italy, ${ }^{3}$ Institute of Biotechnology, University of Helsinki, Finland, ${ }^{4}$ Dipartimento di Scienze Biomorfologiche e Funzionali, University Federico II, Napoli, Italy, ${ }^{5}$ Dipartimento di Scienze Ostetriche, Ginecologiche ed Urologiche e Fisiopatologia della Riproduzione, University Federico II, Napoli, Italy and ' Istituto di Endocrinologia ed Oncologia Sperimentale (IEOS) del CNR, Napoli, Italy

Email: Anna Conti - anconti@unina.it; Floriana Fabbrini - ffabbrin@unina.it; Paola D'Agostino - dagostinop@libero.it; Rosa Negri - rosnegri@unina.it; Dario Greco - dario.greco@helsinki.fi; Rita Genesio - rgenesio@unina.it; Maria D'Armiento - darmiento@unina.it; Carlo Olla - colla@libero.it; Dario Paladini - paladini@unina.it; Mariastella Zannini - stella@szn.it; Lucio Nitsch* - nitsch@unina.it

* Corresponding author †Equal contributors

Published: 7 August 2007

BMC Genomics 2007, 8:268 doi:10.1/86/147|-2164-8-268
Received: 9 May 2007

Accepted: 7 August 2007

This article is available from: http://www.biomedcentral.com/I47I-2/64/8/268

(C) 2007 Conti et al; licensee BioMed Central Ltd.

This is an Open Access article distributed under the terms of the Creative Commons Attribution License (http://creativecommons.org/licenses/by/2.0), which permits unrestricted use, distribution, and reproduction in any medium, provided the original work is properly cited.

\begin{abstract}
Background: The Down syndrome phenotype has been attributed to overexpression of chromosome 2I (Hsa2l) genes. However, the expression profile of $\mathrm{Hsa} 2 \mathrm{I}$ genes in trisomic human subjects as well as their effects on genes located on different chromosomes are largely unknown. Using oligonucleotide microarrays we compared the gene expression profiles of hearts of human fetuses with and without Hsa2I trisomy.

Results: Approximately half of the 15,000 genes examined ( 87 of the 168 genes on $\mathrm{Hsa} 2 \mathrm{I}$ ) were expressed in the heart at 18-22 weeks of gestation. Hsa2I gene expression was globally upregulated $\mathrm{I} .5$ fold in trisomic samples. However, not all genes were equally dysregulated and 25 genes were not upregulated at all. Genes located on other chromosomes were also significantly dysregulated. Functional class scoring and gene set enrichment analyses of 473 genes, differentially expressed between trisomic and non-trisomic hearts, revealed downregulation of genes encoding mitochondrial enzymes and upregulation of genes encoding extracellular matrix proteins. There were no significant differences between trisomic fetuses with and without heart defects.
\end{abstract}

Conclusion: We conclude that dosage-dependent upregulation of $\mathrm{Hsa2I}$ genes causes dysregulation of the genes responsible for mitochondrial function and for the extracellular matrix organization in the fetal heart of trisomic subjects. These alterations might be harbingers of the heart defects associated with $\mathrm{Hsa} 2 \mathrm{I}$ trisomy, which could be based on elusive mechanisms involving genetic variability, environmental factors and/or stochastic events. 


\section{Background}

Down syndrome (DS) is the most frequent autosomal aneuploidy that is compatible with post-natal life. It results from complete or partial trisomy of chromosome 21 (Hsa21) and is characterized by a complex phenotype in which over 80 features occur with various degrees of expression and frequency [1]. Down syndrome is a major cause of congenital heart defects (CHD). It is associated mostly with endocardial cushion defects $[2,3]$, the most frequent being atrioventricular canal defects (AVCD) followed by ventricular septal defects (VSD) and tetralogy of Fallot [3].

Attempts to identify the Hsa21 genes that contribute to the DS phenotype have focused on the Down Syndrome Critical Region (DSCR) which spans approximately 5.4 $\mathrm{Mb}$ in band 21q22.3 [4-7]. The DSCR hypothesis predicts that a gene, or genes, in this region are sufficient to produce the specific DS features when present in three copies. A narrowed region was also proposed as the candidate region for DS-CHD [8]. The DSCR hypothesis was tested in mice $[9,10]$ and it was found that trisomy for DSCR alone is necessary but not sufficient for brain phenotypes in trisomic mice. These results suggest that the origins of trisomic phenotypes are even more complicated than formerly assumed and that they probably involve multiple gene interactions [10]. It has been proposed that the complex phenotypic alterations of DS could result from an interplay between Hsa21 genes and developmentally regulated genes elsewhere on the genome [11] and that the loss of genetic balance in pivotal processes regulating development might increase susceptibility to genetic and environmental insults [12].

The mechanism by which an extra copy of chromosome 21 produces the DS phenotype is unknown and is possibly complex. It has been postulated that a triplicated chromosome 21 causes a 50\% increase in the expression of trisomic genes as a primary dosage effect [13]. With the advent of microarrays and other high-throughput technologies, it became possible to demonstrate this primary dosage effect. By measuring the steady-state-RNA levels in human DS tissues and cells [14-17] and in tissues from mouse models of DS [18-22] it has been established that the trisomy causes an overall 50\% increase in the RNA levels of Hsa21 genes. At least some of this RNA increase might result in perturbations of the pathways and cellular processes in which these genes function [23]. This can affect cardiac development and result in CHD [16].

Given the number of candidate genes involved, the number of alternative splice variants of individual genes and the number of pathways in which these genes function, pathway analysis seems the most suitable approach to the study of genotype/phenotype correlations in DS
[23]. Data from functional studies suggest that multiple chromosome 21 genes affect protein processing, mitochondrial function and reactive oxygen species production, one-carbon metabolism and cell adhesion [24]. Mitochondrial function and reactive oxygen pathways are already targets in the study of neurodegeneration [25-28].

In this study we determined the transcription profile of Hsa21 genes in the heart of human fetuses at 18-22 weeks of gestation. Our goal was to understand how upregulation of Hsa21 genes may influence the expression of genes mapping on other chromosomes and potentially involved in CHD. We investigated the differential gene expression and pathway dysregulation associated with Hsa21 trisomy in fetal hearts using DNA microarray technology and functional analysis. By comparing heart samples from fetuses with or without Hsa21 trisomy, we observed the upregulation of most, but not all, Hsa21 genes as well as the differential expression of genes located on different chromosomes. We found that downregulation of several mitochondrial genes and upregulation of many extracellular matrix genes was a common feature of all trisomic hearts.

\section{Results \\ General}

Cardiac tissue was obtained from fetuses at 18-22 weeks of gestation after therapeutic abortion. Ten samples from fetuses trisomic for Hsa21 and 5 from euploid, control fetuses were studied. At autopsy, the phenotype of the fetuses with Hsa21 trisomy was found to be consistent with DS. The presence of CHD was established by direct examination at the time of tissue explantation and was confirmed by histological analysis of a portion of the heart (see Materials and Methods). The demographic data of the analyzed samples are shown in Table 1.

\section{Analysis of the fetal heart transcriptome}

The gene expression profile of the 15 fetal hearts was determined by DNA microarray analysis using Affymetrix HG-U133A oligonucleotide arrays. The 22,283 probe sets represented on the Affymetrix chip corresponded to $\sim 14,500$ genes and 500 expressed sequence tags and clones. Affymetrix Microarray Suite (MAS 5.0) software was used to identify presence calls and to quantify gene expression. We first determined the total number of genes expressed in the fetal hearts by assessing the number of presence calls. Approximately 7,200 probe sets, corresponding to $\sim 5,100$ individual genes, were called present in all the analyzed samples. We also calculated how many genes were called present in at least $2 / 3$ of the samples, and found that $\sim 10,400$ probe sets, corresponding to $\sim 7,500$ individual genes, were called present in at least 10 samples. This might represent a more reliable estimate of expressed genes since the MAS 5.0 software underesti- 
Table I: Characteristics of the samples analyzed in the study

\begin{tabular}{|c|c|c|c|c|c|c|}
\hline Telethon Bank ID & Experiment ID & Karyotype & Age (gw) & PMI (h) & Heart defects & GEO accession \\
\hline \multicolumn{7}{|l|}{ NH GROUP } \\
\hline TB 26 & $\mathrm{HI}$ & $46, X Y$ & 20 & 3 & NO & GSM30867 \\
\hline TB 21 & $\mathrm{H} 2$ & $46, X Y$ & 21 & 3 & NO & GSM30868 \\
\hline TB 30 & $\mathrm{H} 3$ & $46, X Y$ & 20 & 1 & NO & GSM30869 \\
\hline TB 32 & $\mathrm{H} 4$ & $46, X X$ & 21 & I & NO & GSM30870 \\
\hline TB 23 & $\mathrm{H} 5$ & $46, X X$ & 21 & 4 & NO & GSM3087I \\
\hline \multicolumn{7}{|l|}{ DSH GROUP } \\
\hline TB 37 & $\mathrm{DHI}$ & $47, X Y,+21$ & 21 & 2 & NO & GSM30862 \\
\hline TB 43 & $\mathrm{DH} 3$ & $47, X Y,+21$ & 20 & 3 & NO & GSM30863 \\
\hline TB 50 & $\mathrm{DH} 4$ & $47, X Y,+21$ & 20 & 3 & NO & GSM30864 \\
\hline TB 47 & $\mathrm{DH} 5$ & $47, X Y,+21$ & 19 & 4 & NO & GSM30865 \\
\hline TВ 48 & $\mathrm{DH} 6$ & $47, X Y,+21$ & 21 & 3 & NO & GSM30866 \\
\hline TB 9 & $\mathrm{CDHI}$ & $47, X Y,+21$ & 22 & 2 & YES & GSM30723 \\
\hline TB 33 & $\mathrm{CDH} 2$ & $47, X Y,+21$ & 20 & 4 & YES & GSM30855 \\
\hline TB 55 & $\mathrm{CDH} 4$ & $47, X X,+21$ & 21 & 2 & YES & GSM30864 \\
\hline TB 22 & $\mathrm{CDH} 5$ & $47, X X,+21$ & 18 & 3 & YES & GSM30859 \\
\hline TB 57 & $\mathrm{CDH} 6$ & $47, X X,+21$ & 20 & 3 & YES & GSM30860 \\
\hline
\end{tabular}

Experiment accession is GSEI789

DSH $=$ Heart samples from fetuses with trisomy of $\mathrm{Hsa2} I$

$\mathrm{NH}=$ Heart samples from control fetuses

ID = identifier numbers

$\mathrm{gw}$ = gestational weeks

PMI(h) = Post-mortem interval (hours)

Heart defects: TB9, Fallot's trilogy; TB33, Ventricular Septal Defect; TB55 Atrio-Ventricular Canal Defect; TB22 and TB57, Fallot's Tetralogy.

$\mathrm{GEO}=$ Gene Expression Omnibus

mates presence calls [29]. Expressed genes and their presence calls are reported (see Additional file 1).

\section{Expression of Hsa2 I genes}

The Affymetrix HG-U133A chip includes 262 probe sets that correspond to 168 known genes mapping on Hsa21. Eighty-one probe sets, corresponding to 63 individual genes, were called present in all analyzed samples. If we consider genes called present in at least 10 out of 15 samples, 117 probe sets, corresponding to 87 Hsa21 genes, might be regarded as being expressed in the human heart at 18-22 weeks of gestation (see Additional file 2). To investigate whether Hsa21 genes were upregulated in the heart tissue of DS fetuses, we compared the mean raw logtransformed gene expression data from DS heart tissues (DSH group) with the mean control sample values (NH group). The $\mathrm{DSH} / \mathrm{NH}$ ratio was $1.48 \pm 0.35$ for Hsa21 genes and $\sim 1$ for all chromosomes or for any other chromosome (Figure 1). This difference was highly significant ( $\mathrm{p}<0.0001$; ANOVA test with Bonferroni post-hoc). Scatter plot of DSH versus $\mathrm{NH}$ expression data shows that more than $75 \%$ of Hsa21 genes had a $\mathrm{DSH} / \mathrm{NH}$ ratio above 1 , whereas genes mapping on all other chromosomes were almost equally distributed above and below the line corresponding to the ratio $=1$ (see Additional file
3). The level of variation of expression of Hsa21 genes was not very high, with a fold change ranging from 1.2 to 3 . Twenty-five genes had a fold change below 1.2 (see Additional file 2). Quantitative real-time PCR (qRT-PCR) analyses performed on $14 \mathrm{Hsa} 21$ genes, either upregulated or not in DS samples, were in good agreement with the microarray results (Table 2).

\section{Analysis of differentially expressed genes}

We compared the gene expression levels in DSH versus $\mathrm{NH}$ fetuses. To this aim, raw expression data were normalized and pre-filtered to eliminate unreliable data, thus 8,966 probe sets, corresponding to $\sim 6,300$ genes, were considered for further analysis. Reliable gene expression data with fold change DSH vs. $\mathrm{NH}>|1.2|$ and $\mathrm{p}<.05$ were filtered. A total of 473 genes were significantly either downregulated (278 genes) or upregulated (195 genes) in the DSH group versus the NH group (Figure 2). Thirty-two of the upregulated genes were located on Hsa21 and thereof 441 dysregulated genes were on different chromosomes (see Additional file 4).

Gene Ontology functional class scoring (GOTM software) was performed by comparing the list of differentially expressed genes to the complete set of genes spotted on 


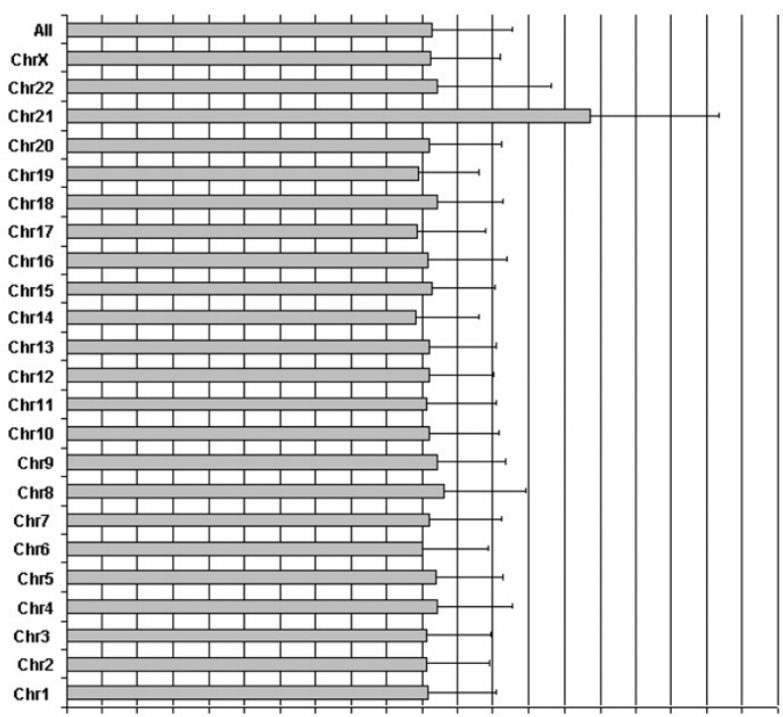

$\begin{array}{lllllllllllllllllllll}0,0 & 0,1 & 0,2 & 0,3 & 0,4 & 0,5 & 0,6 & 0,7 & 0,8 & 0,9 & 1,0 & 1,1 & 1,2 & 1,3 & 1,4 & 1,5 & 1,6 & 1,7 & 1,8 & 1,9 & 2,0\end{array}$

DSH/NH ratio

\section{Figure I}

DSH/NH ratio of gene expression calculated for each chromosome and for all the chromosomes. Cumulative gene expression (raw data) was calculated for each chromosome and for all chromosomes and expressed as ratio between DSH and NH samples. Differences among chromosomes were evaluated using the ANOVA one-way test with Bonferroni post-hoc multiple comparison test. Only the difference between Hsa2 I and any other chromosome is significant $(p<0.0001)$. Other comparisons among chromosomes are not statistically significant. The mean $\mathrm{DSH} / \mathrm{NH}$ s ratio is $\sim$ I for all the chromosomes and I.48 \pm 0.35 for Hsa2I. DSH = Heart samples from fetuses with Hsa2I trisomy (includes the samples: $\mathrm{CDH}, \mathrm{CDH} 2, \mathrm{CDH} 4, \mathrm{CDH} 5, \mathrm{CDH} 6$ from fetuses with heart defects, and the samples: $\mathrm{DHI}, \mathrm{DH} 3$, $\mathrm{DH} 4, \mathrm{DH}$, DH6 from fetuses without heart defects). $\mathrm{NH}=$ Heart samples from control non trisomic fetuses (includes the samples: $\mathrm{HI}, \mathrm{H} 2, \mathrm{H} 3, \mathrm{H} 4, \mathrm{H} 5)$.

the Affymetrix HG-U133A chip, chosen as reference list. Forty-four enriched categories for downregulated genes (Table 3) and 19 enriched categories for upregulated genes (Table 4) were identified. The ratios between observed and expected genes for the most represented GO categories and their p-values are reported (Tables 3 and 4 ). The most enriched GO cellular component categories were mitochondrial-related, for downregulated genes, and extracellular matrix (ECM)-related, for upregulated genes. At least 65 genes encoding mitochondrial enzymes were downregulated in the DS heart tissue out of the 650 probe sets for mitochondrial proteins spotted on the HGU133A chip (530 detected in heart tissue), and 40 genes out of the $\sim 700$ probe sets encoding ECM proteins (340 detected in the heart tissue), were upregulated in DSH samples (see Additional file 5).
Pathway analysis with Pathway Miner software revealed that 'oxidative phosphorylation' (OXPHOS) was the pathway most influenced by Hsa21 trisomy, because at least 16 genes out of the 119 represented on the chip, were downregulated in Hsa21 trisomy and no upregulated oxidative phosphorylation genes were detected (Figure 3). The second most affected pathway was 'focal adhesion', which contained upregulated genes that mostly encode ECM proteins (Figure 3).

To verify that these results were not affected by the methods of data processing and data analysis, a list of differentially expressed genes was generated after a different preprocessing method (gcRMA) and the functional analysis was performed with a different software tool, the Gene Set Enrichment Analysis (GSEA) [30]. A total of 532 genes (49 located on Hsa21), with a fold change higher than $|1.2|$ and $\mathrm{p}<.05$, were found to be differentially expressed in the comparison between DSH and NH samples (see Additional file 6). Using the GSEA to identify gene sets that correlated with the DS condition, we obtained five biologically informative gene sets (see Additional file 7). These included two sets of genes whose upregulation was highly correlated with DS (ECM and Cell Adhesion), and three sets of genes whose downregulation was highly correlated with DS (Mitochondria, Electron Transport Chain and OXPHOS). These results are in very good agreement with functional analysis carried out with MAS 5.0 preprocessed data and the GOTM and Pathway Miner web tools.

Unsupervised classification of samples based on the similarity of expression data across a gene list of 900 genes, not mapping to Hsa21 and encoding mitochondrial and ECM proteins, yielded a condition tree in which trisomic samples are perfectly separated from control samples (see Additional file 8).

The results of microarray analysis were confirmed by qRTPCR for 9 OXPHOS genes and for 7 ECM genes (Table 2).

\section{Expression of DYRKIA, DSCRI and NFATc genes}

The calcineurin/NFAT signaling pathway is known to be a critical regulator of organogenesis [31] and the NFATc transcription factors are transiently expressed in the endocardial cushions during heart septation [32]. The DSCR1 and DYRK1A genes, both mapping on Hsa21 within the critical region for DS, act synergistically to prevent nuclear translocation of NFATc transcription factors and may cause their downregulation [33]. We therefore examined the expression of DYRK1A and DSCR1 and of genes of the calcineurin pathway (NFATc1-4) in DSH and NH samples. DYRK1A was upregulated and NFATc2 downregulated in the trisomic heart samples (Table 2, p <.05). NFATc 3 was also downregulated $(\mathrm{p}<.06)$. DSCR1 expres- 
Table 2: Average expression ratios (DS samples/controls) calculated from microarray and RT-PCR data and Pearson correlation coefficient (r) between microarray and RT-PCR data. Hsa2I genes are in bold.

\begin{tabular}{|c|c|c|c|c|c|c|c|c|}
\hline Functional Category & Probe ID & Gene Name & GenBank & Micro-array Fold change & Micro-array p-value & RT-PCR ratio & $r$ & Primers for RT-PCR \\
\hline \multirow[t]{9}{*}{ Oxydative Phospho-rylation } & 201226_at & NDUFB8 & NM 005004 & 0.65 & 0.0160 & 0.76 & 0.78 & $\begin{array}{l}\text { LEFT-GCCAAGAAGTATAATATGCGTGTG } \\
\text { RIGHT-GTCAGGGAGCTTCGGGTAG }\end{array}$ \\
\hline & 201740_at & NDUFS3 & NM $00455 I$ & 0.76 & 0.0294 & 0.60 & 0.88 & $\begin{array}{l}\text { LEFT-GATTATGGCTTCGAGGGACA } \\
\text { RIGHT-ACCCGCTTCACTTCATCATC }\end{array}$ \\
\hline & 201903_at & UQCRCI & $\underline{N M \quad 003365}$ & 0.77 & 0.0142 & 0.89 & 0.84 & $\begin{array}{l}\text { LEFT-CCGAGCAGTCCTCTCAGC } \\
\text { RIGHT-TGTTCCCTTGAAAGCCAGAT }\end{array}$ \\
\hline & 201966_at & NDUFS2 & NM 004550 & 0.67 & 0.0010 & 0.58 & 0.89 & $\begin{array}{l}\text { LEFT-GAATGGGCACAGCAGTTTG } \\
\text { RIGHT-GGCCCAAAGTTCAGGGTAAT }\end{array}$ \\
\hline & 203606_at & NDUFS6 & NM 004553 & 0.75 & 0.0464 & 0.63 & 0.84 & $\begin{array}{l}\text { LEFT-AGAAGGTCACGCACACTGG } \\
\text { RIGHT-CACGGGCTGCTCTGCTAT }\end{array}$ \\
\hline & 203663_s_at & $\operatorname{cox} 5 \mathrm{~A}$ & NM 004255 & 0.79 & 0.0400 & 1.04 & 0.79 & $\begin{array}{l}\text { LEFT-AACTGGGCCTTGACAAAGTG } \\
\text { RIGHT-GGTAACTGTTCACACTCAAGTAGCA }\end{array}$ \\
\hline & 203858_s_at & coxio & NM 001303 & 0.77 & 0.0101 & 0.66 & 0.92 & $\begin{array}{l}\text { LEFT-CTTTTGACTGGCCCTGTTTC } \\
\text { RIGHT-ACCAGCGGTCTGTTCTTTGT }\end{array}$ \\
\hline & 218160_at & NDUFA8 & NM 014222 & 0.73 & 0.0445 & 0.71 & 0.94 & $\begin{array}{l}\text { LEFT-GTCATGCCGGGGATAGTG } \\
\text { RIGHT-TTAAGCACAGCAGAACTAATTTTCA }\end{array}$ \\
\hline & 218190_s_at & UCRC & NM 013387 & 0.76 & 0.0017 & 0.76 & 0.89 & $\begin{array}{l}\text { LEFT-GACGCTATCTACGACCACATCA } \\
\text { RIGHT-GGTCCTTCTGGCCTGGAT }\end{array}$ \\
\hline \multirow[t]{7}{*}{ Extra-cellular Matrix } & 201069_at & MMP2 & NM 004530 & 1.59 & 0.0069 & 1.89 & 0.93 & $\begin{array}{l}\text { LEFT-TCCACCACCTACAACTTTGAGA } \\
\text { RIGHT-AACTTGCAGGGCTGTCCTT }\end{array}$ \\
\hline & 202310_s_at & COLIAI & $\underline{\mathrm{K} 0 \mid 228}$ & 1.55 & 0.0333 & 5.86 & 0.90 & $\begin{array}{l}\text { LEFT-TGTTCAGCTTTGTGGACCTC } \\
\text { RIGHT-CTGTACGCAGGTGATTGGTG }\end{array}$ \\
\hline & 202403_s_at & COLIA2 & NM 000089 & 1.60 & 0.0192 & 3.59 & 0.77 & $\begin{array}{l}\text { LEFT-CACATGCCGTGACTTGAGAC } \\
\text { RIGHT-TAGCATCCATAGTGCATCCTTG }\end{array}$ \\
\hline & 202994_s_at & FBLNI & $\underline{Z 95331}$ & 1.72 & 0.0271 & 2.38 & 0.89 & $\begin{array}{l}\text { LEFT-GCCACAAGTGCGAGAACAC } \\
\text { RIGHT-TAGACGTTGGCACACTCCTG }\end{array}$ \\
\hline & 20908I_s_at & COLI8AI & AFOI808I & 1.57 & 0.0079 & 1.91 & 0.95 & $\begin{array}{l}\text { LEFT-GTGGCCCTCTACGTGGACT } \\
\text { RIGHT-TCTGAGTCATCGCCTTCCTC }\end{array}$ \\
\hline & 213428_s_at & COL6AI & $\underline{\mathrm{AA} 292373}$ & 1.62 & 0.0493 & 2.20 & 0.78 & $\begin{array}{l}\text { LEFT-AGGAGACCCTGGTGAAGCTG } \\
\text { RIGHT-AGGTCCTGGGGCTCCTCT }\end{array}$ \\
\hline & 209156_s_at & COL6A2 & AY029208 & 2.39 & 0.0002 & 2.18 & 0.79 & $\begin{array}{l}\text { LEFT-GACCTGGTCGCTGAGAAGTT } \\
\text { RIGHT-GCCTTGTGGAAGTTCTGCTC }\end{array}$ \\
\hline \multirow[t]{13}{*}{ Other genes } & 205548_s_at & BTG3 & NM006806 & 1.68 & 0.0134 & 1.62 & 0.83 & $\begin{array}{l}\text { LEFT-GAGGCAGTTGAGAGGTTTGC } \\
\text { RIGHT-GAGTGAGCTCCTTTGGAAG }\end{array}$ \\
\hline & 35776_at & ITSNI & AF064243 & 1.72 & 0.0003 & 1.57 & 0.88 & $\begin{array}{l}\text { LEFT-GTGAGCGGCACTGATTTGT } \\
\text { RIGHT-GATCATGCTTCGCTCTTTCC }\end{array}$ \\
\hline & 205593_s_at & PDE9A & NM 002606 & 2.05 & 0.0067 & 2.05 & 0.89 & $\begin{array}{l}\text { LEFT-CAGAACGCACTCCGTACAAA } \\
\text { RIGHT-TGGGCTCTACCTGTCCACTT }\end{array}$ \\
\hline & 211065_x_at & PFKL & $\underline{\mathrm{BC} 006422}$ & 1.42 & 0.0088 & 1.97 & 0.81 & $\begin{array}{l}\text { LEFT-GGTGGACCTGGAGAAGCTG } \\
\text { RIGHT-TCCAGGCGGAGTCAATGT }\end{array}$ \\
\hline & 200642_at & SODI & NM 000454 & 1.16 & $>0.05$ & 0.65 & 0.83 & $\begin{array}{l}\text { LEFT-GCATCATCAATTTCGAGCAG } \\
\text { RIGHT-CAGCCTCTGTATTATCTCCAA }\end{array}$ \\
\hline & 203405_at & DSCR2 & NM 003720 & 1.15 & $>0.05$ & 0.85 & 0.78 & $\begin{array}{l}\text { LEFT-AAAGACTCGGCGTGTTGTC } \\
\text { RIGHT-GAATTGCTGGGATTTTCCAT }\end{array}$ \\
\hline & 20267I_s_at & PDXK & NM 003681 & 1.12 & $>0.05$ & 1.00 & 0.98 & $\begin{array}{l}\text { LEFT-CATACAGAGCCACGTCATCC } \\
\text { RIGHT-GCATAGCCTGTGTGGTTTGA }\end{array}$ \\
\hline & 202325_s_at & ATP5J & NM 001685 & 1.00 & $>0.05$ & 1.17 & 0.78 & $\begin{array}{l}\text { LEFT-TGTTTGGCTTCTGTCTCACC } \\
\text { RIGHT-GGCTGACCGAATGACAGAG }\end{array}$ \\
\hline & 202749_at & WRB & NM 004627 & 1.17 & $>0.05$ & 1.25 & 0.85 & $\begin{array}{l}\text { LEFT-CTCAGCTTCGTGTTTGGATG } \\
\text { RIGHT-ACTGTGGAGAGCTCCTGCTT }\end{array}$ \\
\hline & 209033_s_at & DYRKIA & $\underline{\mathrm{D} 86550}$ & 1.53 & 0.0001 & 1.71 & 0.84 & $\begin{array}{l}\text { LEFT-GATATCATATGGGTCAGGTCATTTT } \\
\text { RIGHT-CTGGACTGTAACATAACACAGTATGC }\end{array}$ \\
\hline & 208370_s_at & DSCRI & NM $0044 \mid 4$ & 1.25 & $>0.05$ & 4.35 & 0.83 & $\begin{array}{l}\text { LEFT-TTTGCTCAGACCTTACACATAGGA } \\
\text { RIGHT-GGGAGGGGAGATCAGAAACT }\end{array}$ \\
\hline & 210555_s_at & NFATC3 & $\underline{\mathrm{U} 85430}$ & 0.45 & $>0.05$ & 0.54 & 0.97 & $\begin{array}{l}\text { LEFT-CTTTGCAATGGCAAGAGGA } \\
\text { RIGHT-GATGAGGCACAGGCAAAGAT }\end{array}$ \\
\hline & 217526_at & NFATC2 & $\underline{\mathrm{Al} 478300}$ & 0.77 & 0.019 & 0.67 & 0.84 & $\begin{array}{l}\text { LEFT-GAGTTCACATCCCAGAGTCCA } \\
\text { RIGHT-GAGCACTCGATGGGGTTAGA }\end{array}$ \\
\hline
\end{tabular}




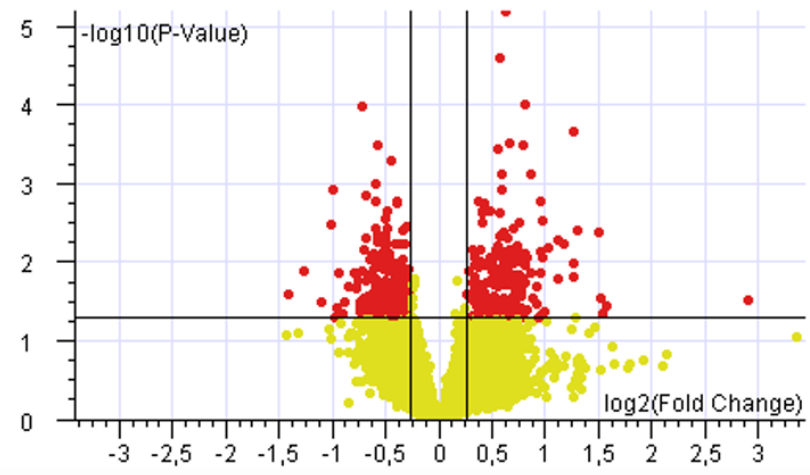

Figure 2

Volcano plot of genes differentially expressed between trisomic and control samples. The log2 of fold change between trisomic and control samples is represented on the $x$-axis and the negative log of $p$-values from the t-test is represented on the y-axis. Genes upregulated in the trisomic samples are on the right of the horizontal axis 0 value; genes downregulated are on the left. Red dots indicate 473 genes that are significantly up- or down-regulated in the trisomic samples compared to the control samples $(p<0.05)$. Yellow dots indicate genes with no significant variation.

sion in fetal hearts varied greatly among individual samples. It was not overall significantly up- or downregulated, but its expression pattern was inversely correlated with that of NFATc3, independently of trisomy or cardiopathy (Figure 4). The Pearson correlation coefficient (r) was equal to $-0.66(\mathrm{r} 2=0.44), \mathrm{p}<0.01$.

\section{Comparison between DS heart samples with and without CHD}

The differential expression analysis of DS fetuses with $(\mathrm{CDH})$ and without $(\mathrm{DH})$ cardiac defects revealed a strong homogeneity between the 2 groups. Only 42 genes were differentially expressed, 19 upregulated and 23 downregulated in the $\mathrm{CDH}$ group, with a fold change ranging from $|1.2|$ to $|2|, \mathrm{p}<.05$ (Figure 5a). None of these genes mapped on Hsa21. The same functional analysis that was used to compare trisomic and control samples did not produce any significant result when genes differentially expressed in CDH vs. DH were considered. Similarly, there were no differences in the expression of mitochondrial and ECM genes between DS fetuses with and without heart defects (Figure 5b-5c).

\section{Discussion}

Using DNA microarray analysis we have obtained information about transcripts that are present in the human fetal heart at 18-22 weeks of gestation. The data indicate that approximately $50 \%$ of the 15,000 analyzed genes are expressed in human fetal heart. The percentage of Hsa21 genes expressed in fetal hearts was not very different.

\section{Upregulation of Hsa2 I genes}

We found that Hsa21 genes are upregulated in all trisomic fetal hearts. This demonstrates that the concept of increased transcription of Hsa21 genes in Hsa21 trisomy applies to the human heart irrespective of CHD. The level of upregulation is modest. If we consider the mean for all Hsa21 genes analyzed, the fold increase in Hsa21 trisomy hearts versus controls is close to 1.5 . This result is highly significant and confirms that microarrays can detect even small differences in gene expression levels.

This modest gene upregulation is in agreement with data obtained in developing human brain and heart [16,17], as well as in the cerebellum [21,22] and in different tissues [18-20] of adult Ts65Dn and Ts1Cje mice, two animal models of Hsa21 trisomy. Despite the different experimental conditions, an overall fold increase of $\sim 1.5$, which is consistent with a 3:2 ratio between trisomic and euploid fetuses, was reported in all these studies. However, the global 1.5-fold increase does not simply result from a 1.5fold upregulation of each single gene. Indeed, whereas the fold increase for most genes is between 1.4 and 1.8, 8 genes are upregulated more than 2-fold in the DSH group and 25 genes are not upregulated in the DSH and $\mathrm{NH}$ groups. These results, which have been confirmed by qRTPCR and are in agreement with another study [16], are indicative of either compensatory effects or heterogeneity in the regulatory mechanisms of Hsa21 genes. The gene expression level of individual Hsa21 genes in the heart of DS individuals is of central relevance in the effort to understand how Hsa21 trisomy causes CHD. Upregulation of a single gene or a combination of dysregulated genes might be at the base of CHD. Measurement of the levels of proteins corresponding to upregulated genes may shed light on the link between Hsa21 trisomy and CHD; a limited amount of information is available on this issue [34-36].

\section{Downregulation of mitochondrial genes}

Our finding that 441 extra-Hsa21 genes were dysregulated in all trisomic samples supports the hypothesis that genes outside of Hsa21 might play a role in determining DS features [37]. Functional analysis of the genes differentially expressed between trisomic and control samples shows global downregulation of genes encoding mitochondrial proteins, especially enzymes involved in the oxidative phosphorylation pathway. Genes from all five complexes were downregulated suggesting that the corresponding proteins and enzymatic activities might be reduced, and that the mitochondrial function could be consequently impaired. 
Table 3: Enriched GO categories for down-regulated genes, sorted by p-value of the comparison between observed and expected data

\begin{tabular}{|c|c|c|c|c|}
\hline GO Category & Observed & Expected & Ratio & p-value \\
\hline \multicolumn{5}{|l|}{ Biological Process } \\
\hline gener. of precursor metabolites and energy & 30 & 9.78 & 3.07 & $3.31 \mathrm{E}-08$ \\
\hline oxidative phosphorylation & 9 & 1.28 & 7.03 & $4.43 \mathrm{E}-06$ \\
\hline ATP synth. Coupled electron transp. & 6 & 0.49 & 12.24 & $6.55 \mathrm{E}-06$ \\
\hline coenzyme metabolism & 12 & 2.65 & 4.53 & I.26E-05 \\
\hline mitochondrial electron transport & 5 & 0.41 & 12.2 & $3.84 \mathrm{E}-05$ \\
\hline acetyl-CoA metabolism & 5 & 0.56 & 8.93 & 0.000193 \\
\hline electron transport & 15 & 5.51 & 2.72 & 0.000408 \\
\hline main pathways of carbohydrate metabolism & 8 & 1.92 & 4.17 & 0.00065 \\
\hline glucose catabolism & 6 & 1.15 & 5.22 & 0.000966 \\
\hline monosaccharide catabolism & 6 & 1.32 & 4.55 & 0.001998 \\
\hline hexose catabolism & 6 & 1.32 & 4.55 & 0.001998 \\
\hline energy derivation by oxid. of organic comp. & 9 & 2.84 & 3.17 & 0.00214 \\
\hline alcohol catabolism & 6 & 1.35 & 4.44 & 0.00217 \\
\hline Glycolysis & 5 & 0.94 & 5.32 & 0.002329 \\
\hline porphyrin biosynthesis & 3 & 0.28 & 10.71 & 0.002341 \\
\hline porphyrin metabolism & 3 & 0.34 & 8.82 & 0.004372 \\
\hline group transfer coenzyme metabolism & 5 & 1.11 & 4.5 & 0.004859 \\
\hline cellular carbohydrate catabolism & 6 & 1.73 & 3.47 & 0.00756 \\
\hline carbohydrate catabolism & 6 & 1.73 & 3.47 & 0.00756 \\
\hline glucose metabolism & 6 & 1.77 & 3.39 & 0.008491 \\
\hline
\end{tabular}

\section{Molecular Function}

\begin{tabular}{lcccc}
\hline electron carrier activity & 9 & 1.14 & 7.89 & $1.7 \mathrm{E}-06$ \\
NADH dehydrogenase activity & 7 & 0.69 & 10.14 & $4.1 \mathrm{EE}-06$ \\
hydrogen ion transporter activity & 12 & 2.39 & 5.02 & $4.48 \mathrm{E}-06$ \\
oxidoreductase activity, acting on NADH/NADPH & 8 & 1.02 & 7.84 & $6.63 \mathrm{E}-06$ \\
sodium ion transporter activity & 7 & 0.75 & 9.33 & $7.6 \mathrm{EE}-06$ \\
primary active transporter activity & 13 & $8.97 \mathrm{E}-06$ \\
monovalent inorganic cation transporter activity & 12 & 2.58 & 4.65 & $9.83 \mathrm{E}-06$ \\
metal ion transporter activity & 9 & 1.56 & 5.77 & $2.34 \mathrm{E}-05$ \\
oxidoreductase activity & 23 & 10.05 & 2.29 & 0.000172 \\
electron transporter activity & 4.37 & 2.75 & 0.001446 \\
carrier activity & 12 & 6.91 & 2.32 & 0.001523 \\
metal cluster binding & 16 & 0.52 & 7.69 & 0.001633 \\
iron-sulfur cluster binding & 4 & 0.52 & 7.69 & 0.001633 \\
unfolded protein binding & 4 & 2.62 & 3.05 & 0.004727
\end{tabular}

\section{Cellular component}

mitochondrion

mitochondrial envelope

mitochondrial inner membrane

mitochondrial membrane

organelle envelope

envelope

organelle inner membrane

membrane-enclosed lumen

organelle lumen

nucleolus

$\begin{array}{lccc}8 & 10.2 & 4.71 & 3 \mathrm{E}-20 \\ 0 & 2.45 & 4.08 & 0.000163 \\ 8 & 1.61 & 4.97 & 0.000194 \\ 9 & 2.07 & 4.35 & 0.000217 \\ 3 & 4.21 & 3.09 & 0.000296 \\ 3 & 4.25 & 3.06 & 0.000326 \\ 8 & 1.8 & 4.44 & 0.000417 \\ 9 & 8.37 & 2.27 & 0.000692 \\ 9 & 8.37 & 2.27 & 0.000692 \\ 6 & 1.82 & 3.3 & 0.009655\end{array}$


Table 4: Enriched GO categories for upregulated genes, sorted by p-value

\begin{tabular}{|c|c|c|c|c|}
\hline GO categories & Observed & Expected & Ratio & p-value \\
\hline \multicolumn{5}{|l|}{ Biological process } \\
\hline phosphate transport & 8 & 0.98 & 8.16 & 5.27E-06 \\
\hline cell adhesion & 22 & 8.15 & 2.7 & I.8IE-05 \\
\hline anion transport & 9 & 2.15 & 4.19 & 0.000297 \\
\hline inorganic anion transport & 8 & 1.77 & 4.52 & 0.000378 \\
\hline axonogenesis & 5 & 0.66 & 7.58 & 0.000471 \\
\hline neuron morphogen. during different. & 5 & 0.74 & 6.76 & 0.000807 \\
\hline neurite morphogenesis & 5 & 0.74 & 6.76 & 0.000807 \\
\hline neuron development & 5 & 0.98 & 5.1 & 0.002889 \\
\hline cell development & 6 & 1.45 & 4.14 & 0.003197 \\
\hline neuron differentiation & 5 & 1.14 & 4.39 & 0.005565 \\
\hline neurogenesis & 5 & 1.19 & 4.2 & 0.006627 \\
\hline \multicolumn{5}{|l|}{ Molecular Function } \\
\hline extracellular matrix struct. const. & 10 & 1.25 & 8 & 4. IIE-07 \\
\hline integrin binding & 4 & 0.43 & 9.3 & 0.000833 \\
\hline copper ion binding & 5 & 0.82 & 6.1 & 0.00128 \\
\hline \multicolumn{5}{|l|}{ Cellular Component } \\
\hline extracellular matrix & 22 & 3.55 & 6.2 & $5 \mathrm{E}-12$ \\
\hline collagen & 8 & 0.5 & 16 & $2.08 \mathrm{E}-08$ \\
\hline extracellular region & 35 & 14.17 & 2.47 & $2.83 \mathrm{E}-07$ \\
\hline fibrillar collagen & 4 & 0.16 & 25 & I.24E-05 \\
\hline actin cytoskeleton & 8 & 2.78 & 2.88 & 0.006602 \\
\hline
\end{tabular}

Protein levels of complex I, III and V were found to be decreased in cerebellar and brain regions $[38,39]$, and a reduction of mitochondrial enzyme activity has been reported in platelets from DS patients [40]. Moreover, impaired mitochondrial function, indicated by reduced mitochondrial redox activity and membrane potential, has been observed in DS astrocytes and in primary cultures of DS fibroblasts, [26,27]. More recently it has been reported that the brain of the DS mouse model Ts1Cje has decreased mitochondrial membrane potential and ATP production [25]. These results are indicative of widespread mitochondrial dysfunction in DS. Our data suggest that mitochondrial dysfunction might also occur in DS hearts and that the reduced expression of mitochondrial genes might be the molecular basis of this dysfunction in the heart as well as in other DS tissues. This is probably not a primay effect of gene dosage because genes for mitochondrial function mapping on Hsa21 are either not expressed or not differentially expressed in human fetal hearts.

\section{Upregulation of ECM genes}

Functional analysis of the 473 differentially expressed genes also demonstrates global upregulation of ECM protein genes. This group includes genes encoding adhesion and ECM proteins that map on Hsa21 such as ADAMTS1, ADAMTS5, APP, JAM2, COL6A1, COL6A2 and COL18A1, which are dose-dependently upregulated in trisomic samples, and genes that do not map on Hsa21 such as fibronectin, fibulin, collagen type I, type III, type V, type $\mathrm{XV}$, metalloproteases (MMPs) and several adhesion molecule genes. Overexpression of this gene family is likely to affect cell adhesion properties, possibly determining an increase in adhesiveness. Cells explanted from endocardial cushion derived structures of fetuses with Hsa21 trisomy are more adhesive in vitro than those from controls [41]. A stochastic model has been proposed for septal defects in DS by which higher values of adhesiveness result in deficiencies of the atrio-ventricular canal development associated with clinical variability among individuals based on chance alone $[42,43]$.

Several of the ECM genes upregulated in trisomic samples have been investigated for their potential role in DS cardiopathy. These include collagen type VI and MMPs. Collagen type VI is expressed in the endocardial cushions during septation, persists during valve differentiation and is implicated in endocardial cushion differentiation. Its pronounced expression in Hsa21 trisomy might lead to AVSD [44]. MMPs are involved in cardiac organogenesis by regulating cell proliferation, epithelial to mesenchymal transition, ECM remodeling and degradation. MMP2, in particular, coordinates prelooping stages, heart tube formation and selective ECM degradation. It has an impor- 


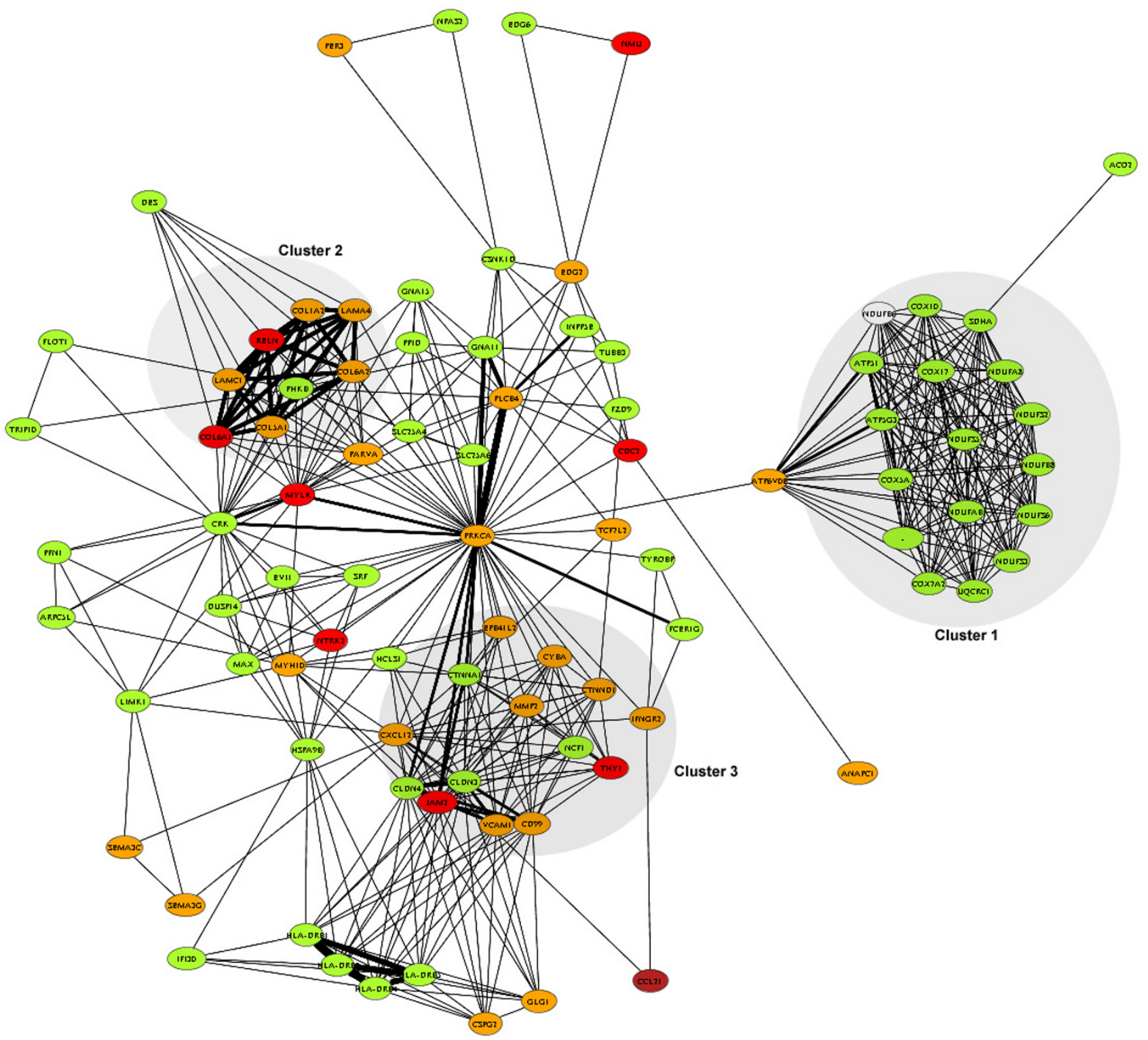

Figure 3

Genes and gene pathways affected by Hsa2 I trisomy. Pathway analysis was performed with Pathway Miner software on the 473 genes dysregulated in trisomic samples. The most affected pathways are: Oxidative Phosphorylation (cluster I), containing 16 genes downregulated in trisomic samples, and Focal Adhesion (cluster 2), containing at least 7 genes upregulated in trisomic samples. Cluster 3 is a network of Cell Adhesion genes, mostly upregulated in trisomic samples. Downregulated genes in cluster I are all mitochondrial genes; upregulated genes in clusters 2 and 3 are mostly ECM genes. Green indicates downregulated genes (darker green $=$ more downregulated); red indicates upregulated genes (darker red $=$ more upregulated).

tant functional role in early cardiogenesis, neural crest cell and cardiac cushion migration and remodeling of the pharyngeal arches and cardiac heart tube $[45,46]$.

It is interesting that DNA microarray analysis from right ventricular biopsies of patients with tetralogy of Fallot demonstrated that genes encoding ECM proteins, such as collagen type I, III, IX, XV and fibronectin, were upregulated versus age-matched controls [47], suggesting that the increase of these ECM proteins has a potential role in CHD. 


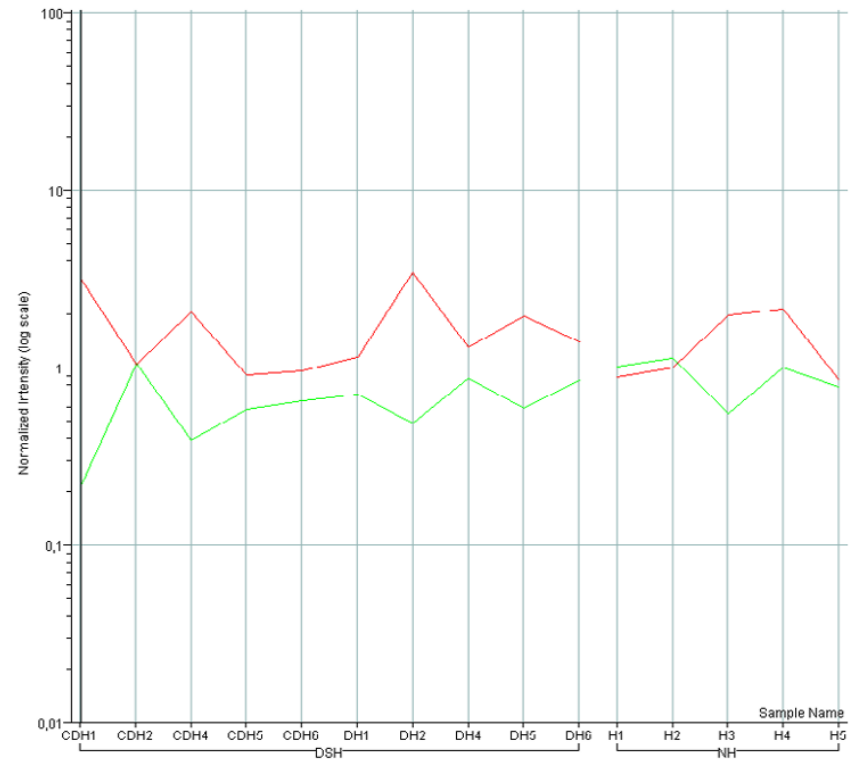

Figure 4

Expression level of DSCRI and NFATC3 genes in individual heart samples. Microarray expression values of DSCRI (red line) and NFATC3 (green line) genes of individual trisomic hearts (CDHI, CDH2, CDH4, CDH5, CDH6 and $\mathrm{DHI}, \mathrm{DH} 3, \mathrm{DH} 4, \mathrm{DH} 5, \mathrm{DH} 6)$ and individual normal hearts $(\mathrm{HI}, \mathrm{H} 2, \mathrm{H} 3, \mathrm{H} 4, \mathrm{H} 5)$ show an inverse correlation $(r=$ $-066)$ between the two genes.

\section{How might Hsa2 I gene upregulation affect the expression} of other genes?

A key issue of DS pathogenesis is to understand how upregulation of Hsa21 genes might dysregulate genes on different chromosomes. Recently, a link has been proposed between two Hsa21 genes, DYRK1A and DSCR1, and the NFATc family of genes. NFATc-null mice show phenotypic anomalies that resemble those observed in human DS and $65 \%$ of NFATc1-4-null mice have endocardial cushion defects [33]. Even modest overexpression of DYRK1A decreases NFATc protein activity and levels and may induce vascular and cardiac defects [33]. DSCR1 also encodes a regulatory protein that is expressed in heart tissue [48] and exerts an inhibitory effect on the calcineurin/NFAT signaling pathway [49], although different protein isoforms may have opposite effects [50]. To verify whether these genes affect the heart of DS fetuses, we evaluated their differential expression both by microarray and by qRT-PCR. Our analyses show that DYRK1A is upregulated and that NFATc2 and NFATc3 are downregulated in Hsa21 trisomic samples. Moreover, an increase in DSCR1 expression in individual hearts correlated with a decrease

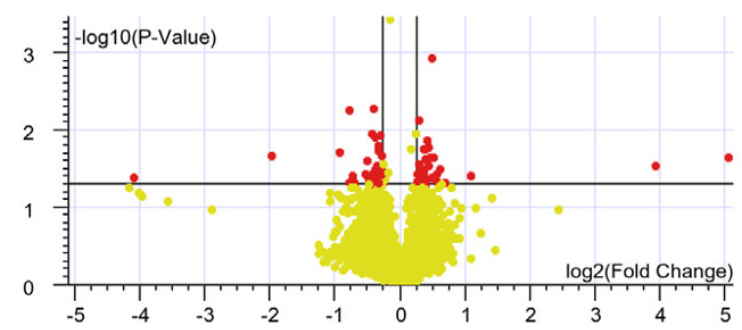

a
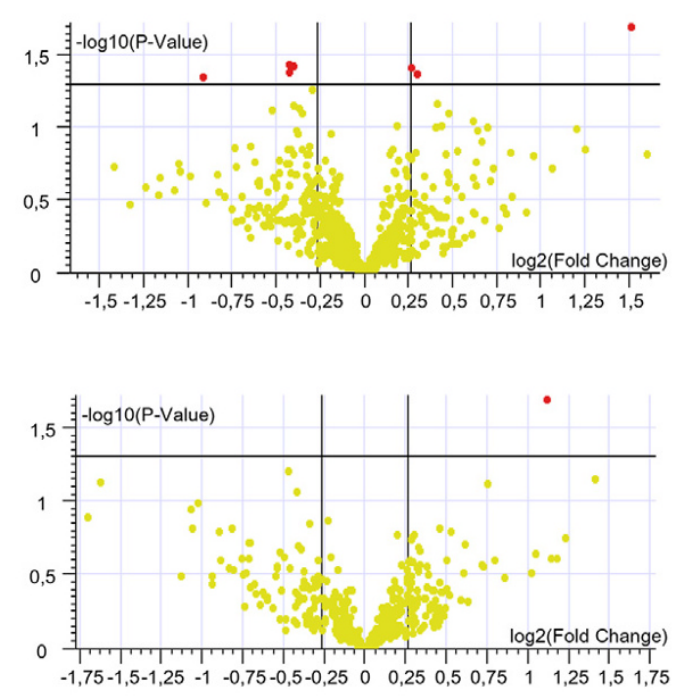

c

\section{Figure 5}

Volcano plots obtained by comparing DS fetuses with and without cardiac defects. Forty-two of the 15,000 analyzed genes are differentially expressed in the 5 samples with cardiac anomalies (CDH) and the 5 samples without cardiac anomalies (DH) (6a). Only a few genes of the $\sim 600$ encoding mitochondrial proteins $(6 \mathrm{~b})$ and of the $\sim 700$ encoding ECM proteins $(6 c)$, are dysregulated in the $\mathrm{CDH}$ vs. $\mathrm{DH}$ comparison. Red dots indicate genes differentially expressed with fold change $>1.2$ and $p<.05$; yellow dots indicate genes with no significant variation.

in NFATc3 expression. Recent data show that the enzymatic activity of complex II and IV of the respiratory chain and mitochondrial oxidative activity are reduced in Nfatc3-/-; Nfatc4-/- cardiomyocytes [51] suggesting that the calcineurin/NFAT pathway affects mitochondrial activity during heart development. We propose that upregulation of DIRK1A and/or DSCR1 in DS might affect mitochondrial gene expression, and thereafter mitochondrial function, through the calcineurin/NFAT pathway. Mitochondrial abnormalities and a decrease of COX activity might also be induced by overproduction of beta APP [52], a gene mapping on Hsa21, although the TS1Cje mouse model, in which APP is not triplicated, also shows 
decreased mitochondrial function and ATP production [25]. The transcription factor GABPalpha, which is encoded by a gene on Hsa21, is another regulator of the expression of genes involved in mitochondrial respiration [28]. However, GABPalpha was not expressed in fetal hearts at 18-22 weeks of gestation, although it cannot be excluded that it is expressed at different embryonic or fetal stages.

Type VI collagen gene upregulation also sheds light on the potential interplay between Hsa21 genes and genes on different chromosomes. Type VI collagen, together with other collagens, is an activator of discoidin domain receptor tyrosine kinases (DDRs) $[53,54]$. Activated DDRs, in turn, induce the expression of metalloproteases such as MMP1 and MMP2 [53] and of other ECM proteins [55]. Moreover, DDR1 and DDR2 are upregulated in trisomic heart samples (see Additional file 4) and DDR2 expression has been detected by confocal microscopy in developing heart, within the cardiac cushions and eventually within the septum [56].

\section{Conclusion}

The expression of most Hsa21 genes and of many genes located on other chromosomes were dysregulated in the heart of trisomic fetuses at 18-22 weeks of gestation. Genes encoding mitochondrial enzymes were significantly downregulated, whereas genes encoding ECM proteins were upregulated in all trisomic hearts, irrespective of CHD. In fact, gene expression did not differ between DS heart samples with or without cardiopathy. This might be due to some intrinsic limits of our approach (e.g., heart developmental stage, and number of samples and genes analyzed). We nevertheless demonstrate that the expression of several gene categories is dysregulated in the hearts of all DS fetuses, and suggest that this dysregulated expression might be a prelude to heart defects. Other factors, such as differences in the genetic background, different Hsa21 haplotypes, stochastic and/or environmental factors, could play a critical role in determining the final pathogenetic result. Finally, non-coding mRNAs as well as conserved non-genic sequences, which have been described within Hsa21, might be implicated in determining the DS phenotype [57].

\section{Methods}

\section{Experimental design}

Fifteen human fetuses from 18- to 22-week-gestation with and without Hsa21 trisomy were analyzed. Ten were trisomic for Hsa21; 5 non trisomic fetuses served as controls. Diagnosis, gestational age, gender and karyotype are provided in Table 1. Control samples were euploid fetuses without cardiac anomalies. Fetuses $\mathrm{H} 1$ and $\mathrm{H} 5$ were aborted because of the mother's condition; they did not show any disorder at autopsy examination. Two other fetuses were affected by genetic anomalies: fragile $\mathrm{X}$ syndrome (H2) and thalassemia (H4). Fetus H3 was affected by severe hydropia. The experimental design was diseased versus control comparison. The conditions tested were gene expression at 18-22 weeks of gestation and genetic variation.

\section{Samples}

Heart tissue was used for total RNA extraction. All cardiac samples were obtained from the Telethon Bank of Fetal Biological Samples at the University of Naples. We used protocols approved by our Institutional Ethics Committee. The hearts were explanted from fetuses after therapeutic abortion. The posterior half, representative of all four chambers, was dissected by a longitudinal cut and immediately frozen in liquid nitrogen and stored at $-135^{\circ} \mathrm{C}$ for RNA extraction. The anterior half was paraffin-embedded. Fetal karyotype was determined on amniocytes, and was confirmed on cultured fibroblasts, by standard cytogenetic methods with G banding.

\section{Microarray hybridization procedure}

All experiments were performed with Affymetrix HGU133A oligonucleotide arrays (Affymetrix, Santa Clara, CA), as described at [58]. Total RNA from each sample was extracted using TRIzol reagent (Gibco/BRL Life Technologies, Inc., Gaithersburg, MD) and used to prepare biotinylated target cRNA, according to the Affymetrix recommendations [58]. Purification of PolyA+ mRNA from total RNA was performed with the Oligotex mRNA Kit (QIAGEN GmbH, Hilden, Germany): $1 \mu \mathrm{g}$ of mRNA was used to generate first-strand cDNA by using a T7-linked oligo(dT) primer; after second-strand synthesis, in-vitro transcription was performed with biotinylated UTP and CTP using the Enzo BioArray High Yield RNA Transcript Labeling Kit (Enzo Diagnostics, Farmingdale, NY), resulting in approximately 100 -fold amplification of RNA. The target cRNA generated from each sample was processed as recommended by the manufacturer and using an Affymetrix GeneChip Instrument System. Fragmentation of biotinylated cRNA, washing and staining were done according to the instructions provided by Affymetrix. Briefly, spike controls were added to $10 \mu \mathrm{g}$ fragmented cRNA before overnight hybridization. Arrays were then washed and stained with streptavidin-phycoerythrin, before being scanned on an Affymetrix GeneChip scanner. Quality and amount of starting RNA was confirmed using spectrophotometry and agarose gel electrophoresis. A detailed description of these procedures is available [58].

\section{Data acquisition and processing}

After scanning, array images were assessed by eye to confirm scanner alignment and the absence of significant bubbles or scratches on the chip surface. $3^{1} / 5^{\prime}$ ratios for GAPDH and beta-actin were confirmed to be within 
acceptable limits (0.70-1.64), and BioB spike controls were found to be present on all chips, with BioC, BioD and CreX also present in increasing intensity. Expression data were deposited in the Gene Expression Omnibus repository [59] with experiment accession number GSE1789.

Using the Affymetrix Software Microarray Suite (MAS $5.0)$, each probe set was assigned an "average difference" value corresponding to the expression level of the particular gene it represented. To make comparisons across different chips, data sets on each chip were scaled to a targeted total fluorescence of 100 . When scaled to a target intensity of 100 (using Affymetrix MAS 5.0 array analysis software), scaling factors for all arrays were within acceptable limits (0.69-1.51), as were background, Q values and mean intensities. Affymetrix software also assigns each probe set an absolute call (present, absent or marginal), which represents a qualitative indication of whether or not a transcript is detected within a sample.

Array scanning data (CEL files) were also pre-processed using the gcRMA algorithm [60]. Raw data were prefiltered to exclude fluorescence intensities lower than 10 , which are indistinguishable from background. Unreliable genes were also discarded using the cross gene error model [61]. This analysis showed an overall $90 \%$ agreement with the MAS 5.0 data analysis; $40 \%$ of this agreement was for fold change only, but the p-value was higher.

GeneSpring software (Silicon Genetics, Redwood City, CA) was used for data mining. Raw expression data were normalized per gene by dividing each measurement for each gene by the median of that gene's measurements in the corresponding control non trisomic samples. Normalized data were log-transformed. Based on Affymetrix absolute call, we determined the total number of genes that were expressed (i.e. called present) in human fetal heart.

Although the Affymetrix chip HG-U133A can measure the expression of $\sim 15,000$ genes, the true transcript level is often affected by a substantial amount of noise and variability induced by many sources including the manufacturing processes and the experimental procedures [62]. We pre-filtered expression data to reduce noise and so discard "unreliable" genes. The Cross-Gene error model [61] was applied to estimate measurement precision by combining variability of gene expression data and assuming that measurements with higher control strength are relatively more precise than measurements with lower control strength. After pre-filtering, genes were considered suitable for differential evaluation if called present in at least 2 out of 15 samples and with a raw signal higher than 10.0. Statistical evaluation of the differential analysis was per- formed by one way ANOVA. The threshold for statistical significance was set to 0.05 .

Unsupervised classification of samples was performed using the hierarchical clustering tool included in the GeneSpring software. A condition tree was generated grouping together DSH or NH samples based on the similarity of their expression data in the specified list.

\section{Bioinformatics data analyses}

Gene ontology functional class scoring was performed using the web-based GOTM software $[63,64]$ which visualizes genes from the list of differentially expressed genes in the GO context, considering as gene sets all the GO categories for biological processes, molecular functions and cellular components. The list of differentially expressed genes was compared to the complete list of genes spotted on Affymetrix HG-U133 chip, in order to identify categories of genes more represented in the list of differentially expressed genes than in the reference gene set.

Pathway analysis was performed by Pathway Miner software $[65,66]$ which catalogs genes of a list based on their role in metabolic, cellular and regulatory pathways from three different pathway databases (GenMap, Encarta and KEGG). A Fisher exact test ranks pathways according to the number of genes of the list which co-occurrs in pathways, considered as gene sets. Furthermore a network is created among genes participating to multiple pathways.

Gene Set Enrichment Analysis (GSEA) was used as described [30] to identify gene sets correlated with the DS condition. The gcRMA output list of differentially expressed genes was ranked per fold change and was submitted to the GSEA tool. Enrichment of functional gene sets from the MSigDB C2 curated database [67] was tested. This database includes sets of genes whose products are involved in specific metabolic and signaling pathways from public databases and sets of genes coregulated in specific conditions. This last group of gene sets was not considered in the analysis. In turn, the Gene Ontology category of Extracellular Matrix genes (GO:31012, cellular component) was added into the MSigDB C2 catalog.

\section{Quantitative Real-Time PCR}

We used the same sources of total RNA for both primary gene expression and validation experiments. cDNA was synthesized with random hexamer primers starting from $1.5 \mu \mathrm{g}$ of total RNA using the reverse transcription protocol (Taqman Reverse Transcription, Applied Biosystems, Applera, Monza, Italia). Real-time PCR was performed using iQ Supermix SYBR Green 2X [68] on the Bio-Rad iCycler [68] according to the manufacturer's protocols. PCR reactions were performed in triplicate. The primers (MWG Biotech, Ebersberg, Germany) used for amplifica- 
tion are listed in Table 2. Primer pairs were designed using the Primer 3 software [69] to obtain amplicons ranging from 100 to150 base pairs, and specifically designed to span introns or cross intron-exon boundaries. In order to test primer efficiency, serial dilutions of cDNAs generated from selected human fetal hearts, that expressed target genes at a suitable level, were used to generate standard curves for each gene. RPL13A and GAPDH housekeeping genes were chosen as reference genes.

\section{List of abbreviations used}

DS $=$ Down syndrome

Hsa21 = Chromosome 21

$\mathrm{CHD}=$ Congenital heart defects

DSH $=$ Heart samples from fetuses with Hsa21 trisomy

$\mathrm{NH}=$ Heart samples from non trisomic fetuses

$\mathrm{DH}=$ Samples without cardiac anomalies

$\mathrm{CDH}=$ Samples with cardiac anomalies

$\mathrm{ECM}=$ Extracellular matrix

OXPHOS = Oxidative phosphorylation

\section{Authors' contributions}

AC supervised the molecular studies, performed the data analysis and drafted the manuscript. FF performed the molecular studies. PDA supervised and participated in the tissue collection and sample preparation. RN contributed to writing the manuscript. DG participated in the data analysis. RG participated in the characterization of the samples. MDA and $\mathrm{CO}$ were responsible for tissue excision and pathology examination. DP performed fetal heart ultrasound analyses and participated in the sample collection. MZ participated in the design of the study and in the molecular studies. LN was responsible for the coordination and supervision of the entire study.

\section{Additional material}

\section{Additional file 1}

Genes expressed in human fetal heart at 18-22 weeks of gestation. Genes are reported if the Affymetrix presence call was 'Present' in at least 10 heart samples. Genes are sorted by alphabetical order.

Click here for file

[http://www.biomedcentral.com/content/supplementary/14712164-8-268-S1.pdf]

\section{Additional file 2}

Hsa21 genes expressed in the human fetal heart at 18-22 weeks of gestation. Genes (probe sets) are sorted according to chromosomal location. Mitochondrial and ECM genes are in bold.

Click here for file

[http://www.biomedcentral.com/content/supplementary/1471-

2164-8-268-S2.pdf]

\section{Additional file 3}

Scatter plot of gene expression data of trisomic samples vs. control samples. Mean raw, log transformed, gene expression data from the 5 control samples (NH) were plotted on the $x$-axis and data from the 10 trisomic samples (DSH) were plotted on the $y$-axis. Plots are shown for Hsa21 genes and for genes of all chromosomes excluding Hsa21. In the plot of Hsa21 more than $75 \%$ of gene probe sets are above the line, whereas in the plot of all other chromosomes approximately the same number of gene probe sets is above and below the line. Abbreviations for DSH and NH are as in Figure 1.

Click here for file

[http://www.biomedcentral.com/content/supplementary/1471-

2164-8-268-S3.pdf]

\section{Additional file 4}

Genes differentially expressed between trisomic and control samples. The table includes genes with fold change $>|1.2|$ and $p<0.05$ (ANOVA test). Genes are sorted according to fold change.

Click here for file

[http://www.biomedcentral.com/content/supplementary/14712164-8-268-S4.pdf]

\section{Additional file 5}

List of downregulated genes encoding mitochondrial proteins, and of upregulated genes encoding extracellular matrix proteins. Hsa21 genes are in bold.

Click here for file

[http://www.biomedcentral.com/content/supplementary/1471-

2164-8-268-S5.pdf]

\section{Additional file 6}

Genes differentially expressed between trisomic and control samples using gc-RMA preprocessed data. The table includes genes with fold change > $|1.2|$ and $p<0.05$ (ANOVA test). Genes are sorted according to fold change. Hsa21 genes are in bold.

Click here for file

[http://www.biomedcentral.com/content/supplementary/1471-

2164-8-268-S6.pdf]

\section{Additional file 7}

Enrichment score plots of the five biologically informative sets correlated to the DS condition with an FDR value $<0.05$. Extracellular matrix and Cell adhesion gene sets are positively correlated to DS condition whereas Mitochondria, Electron transport chain and Oxidative phosphorylation gene sets are negatively correlated. The enrichment score (ES) represents the degree to which a gene set is enriched at the top (positive ES) or at the bottom (negative ES) of our ranked list. The size indicated for each gene set is the dimension of the leading edge subset that is the subset of members of our list that contribute more to the enrichment score (ES). The nominal p-value and the False Discovery Rate (FDR) value estimate the probability that the enrichment score represents a false positive finding. Click here for file

[http://www.biomedcentral.com/content/supplementary/14712164-8-268-S7.pdf] 


\section{Additional file 8}

Condition tree generated using the hierarchical clustering approach. The tree groups samples together based on the similarity of their expression data across a gene list including 1000 genes, not mapping to Hsa21, which encode mitochondrial and ECM proteins. The 15 DS samples are clustered together on the left whereas the five control samples are clustered on the right of the image demonstrating that the expression of genes in the specified list can be used to correctly separate DSH from NH samples. Click here for file

[http://www.biomedcentral.com/content/supplementary/14712164-8-268-S8.pdf]

\section{Acknowledgements}

We thank Prof. E. Vecchione, Prof. P. Martinelli, Dr. F. Leone, Dr. M.V. Locci (Università di Napoli Federico II, Napoli, Italy) for valuable help and suggestions, and $\mathrm{G}$. Gaudioso for his expert technical assistance. We are grateful to Jean Ann Gilder for text editing. We acknowledge the Telethon Bank of Fetal Biological Samples (Telethon Project GTF0 1006) for providing the heart tissue.

This work was supported by grants from BIOGEM (Biotechnology and Molecular Genetics in Southern Italy), from CNR (Consiglio Nazionale delle Ricerche) and from MIUR (Ministero per l'Istruzione, l'Università e la Ricerca).

\section{References}

I. Epstein CJ, Korenberg IR, Anneren G, Antonarakis SE, Ayme S, Courchesne E, Epstein LB, Fowler A, Groner Y, Huret JL, et al.: Protocols to establish genotype-phenotype correlations in Down syndrome. Am J Hum Genet I99|, 49(I):207-235.

2. Ferencz C, Neill CA, Boughman JA, Rubin JD, Brenner JI, Perry LW: Congenital cardiovascular malformations associated with chromosome abnormalities: an epidemiologic study. J Pediatr 1989, I I 4(1):79-86.

3. Park SC, Mathews RA, Zuberbuhler JR, Rowe RD, Neches WH, Lenox CC: Down syndrome with congenital heart malformation. Am J Dis Child 1977, I 3 I (I):29-33.

4. Korenberg JR, Chen XN, Schipper R, Sun Z, Gonsky R, Gerwehr S, Carpenter N, Daumer C, Dignan P, Disteche C, et al: Down syndrome phenotypes: the consequences of chromosomal imbalance. Proc Natl Acad Sci U S A 1994, 9 I (I I):4997-500 I.

5. Delabar JM, Theophile D, Rahmani Z, Chettouh Z, Blouin JL, Prieur $M$, Noel B, Sinet PM: Molecular mapping of twenty-four features of Down syndrome on chromosome 21. Eur J Hum Genet I993, I(2): I |4-I 24.

6. McCormick MK, Schinzel A, Petersen MB, Stetten G, Driscoll DJ, Cantu ES, Tranebjaerg L, Mikkelsen M, Watkins PC, Antonarakis SE: Molecular genetic approach to the characterization of the "Down syndrome region" of chromosome 21. Genomics 1989, 5(2):325-33।

7. Rahmani Z, Blouin JL, Creau-Goldberg N, Watkins PC, Mattei JF, Poissonnier M, Prieur M, Chettouh Z, Nicole A, Aurias A, et al.: Critical role of the D2IS55 region on chromosome $2 I$ in the pathogenesis of Down syndrome. Proc Natl Acad Sci U S A 1989 , 86(15):5958-5962.

8. Barlow GM, Chen XN, Shi ZY, Lyons GE, Kurnit DM, Celle L, Spinner NB, Zackai E, Pettenati MJ, Van Riper AJ, Vekemans MJ, Mjaatvedt $\mathrm{CH}$, Korenberg JR: Down syndrome congenital heart disease: a narrowed region and a candidate gene. Genet Med 200I, 3(2):91-101.

9. Olson LE, Richtsmeier JT, Leszl J, Reeves RH: A chromosome 2 I critical region does not cause specific Down syndrome phenotypes. Science 2004, 306(5696):687-690.

10. Olson LE, Roper RJ, Sengstaken CL, Peterson EA, Aquino V, Galdzicki Z, Siarey R, Pletnikov M, Moran TH, Reeves RH: Trisomy for the Down syndrome "critical region" is necessary but not suffi- cient for brain phenotypes of trisomic mice. Hum Mol Genet 2007, 16(7):774-82.

II. Reeves RH: Down's syndrome. A complicated genetic insult. Lancet 200I, 358 Suppl:S23.

12. Shapiro BL: Whither Down syndrome critical regions? Hum Genet 1997, 99(3):42I-423.

13. Epstein CJ: Developmental genetics. Experientia 1986 42(10): III7-II 28.

14. FitzPatrick DR, Ramsay J, McGill NI, Shade M, Carothers AD, Hastie ND: Transcriptome analysis of human autosomal trisomy. Hum Mol Genet 2002, I I (26):3249-3256.

15. Giannone S, Strippoli P, Vitale L, Casadei R, Canaider S, Lenzi L, D'Addabbo P, Frabetti F, Facchin F, Farina A, Carinci P, Zannotti M: Gene expression profile analysis in human $T$ lymphocytes from patients with Down Syndrome. Ann Hum Genet 2004, 68(Pt 6):546-554.

16. Mao R, Wang X, Spitznagel EL Jr., Frelin LP, Ting JC, Ding H, Kim JW, Ruczinski I, Downey TJ, Pevsner J: Primary and secondary transcriptional effects in the developing human Down syndrome brain and heart. Genome Biol 2005, 6(I3):R I07.

17. Mao R, Zielke CL, Ronald Zielke H, Pevsner J: Global up-regulation of chromosome 21 gene expression in the developing down syndrome brain. Genomics 2003, 8 I (5):457-467.

18. Lyle R, Gehrig C, Neergaard-Henrichsen C, Deutsch S, Antonarakis SE: Gene expression from the aneuploid chromosome in a trisomy mouse model of down syndrome. Genome Res 2004, I4(7): $1268-1274$

19. Kahlem P, Sultan M, Herwig R, Steinfath M, Balzereit D, Eppens B, Saran NG, Pletcher MT, South ST, Stetten G, Lehrach H, Reeves RH, Yaspo ML: Transcript level alterations reflect gene dosage effects across multiple tissues in a mouse model of down syndrome. Genome Res 2004, 14(7): 1258-1267.

20. Amano K, Sago H, Uchikawa C, Suzuki T, Kotliarova SE, Nukina N, Epstein CJ, Yamakawa K: Dosage-dependent over-expression of genes in the trisomic region of $\mathrm{Ts} / \mathrm{Cje}$ mouse model for Down syndrome. Hum Mol Genet 2004, I 3 ( I 3): I 333-1340.

21. Dauphinot L, Lyle R, Rivals I, Dang MT, Moldrich RX, Golfier G, Ettwiller L, Toyama K, Rossier J, Personnaz L, Antonarakis SE, Epstein C), Sinet PM, Potier MC: The cerebellar transcriptome during postnatal development of the TsICje mouse, a segmental trisomy model for Down syndrome. Hum Mol Genet 2005, I4(3):373-384.

22. Saran NG, Pletcher MT, Natale JE, Cheng Y, Reeves RH: Global disruption of the cerebellar transcriptome in a Down syndrome mouse model. Hum Mol Genet 2003, I 2(16):2013-2019.

23. Gardiner K: Gene-dosage effects in Down syndrome and trisomic mouse models. Genome Biol 2004, 5(I 0):244.

24. Gardiner K: Predicting pathway perturbations in Down syndrome. J Neural Transm Suppl 2003:21-37.

25. Shukkur EA, Shimohata A, Akagi T, Yu W, Yamaguchi M, Murayama M, Chui D, Takeuchi T, Amano K, Subramhanya KH, Hashikawa T, Sago H, Epstein CJ, Takashima A, Yamakawa K: Mitochondrial dysfunction and tau hyperphosphorylation in $\mathrm{Ts} I \mathrm{Cje}$, a mouse model for Down syndrome. Hum Mol Genet 2006, I5(I 8):2752-2762.

26. Arbuzova S, Hutchin T, Cuckle $\mathrm{H}$ : Mitochondrial dysfunction and Down's syndrome. Bioessays 2002, 24(8):68I-684.

27. Busciglio J, Pelsman A, Wong C, Pigino G, Yuan M, Mori H, Yankner $B A$ : Altered metabolism of the amyloid beta precursor protein is associated with mitochondrial dysfunction in Down's syndrome. Neuron 2002, 33(5):677-688.

28. O'Leary DA, Pritchard MA, Xu D, Kola I, Hertzog PJ, Ristevski S: Tissue-specific overexpression of the HSA2I gene GABPalpha: implications for DS. Biochim Biophys Acta 2004, I739(I):8I-87.

29. Irizarry RA, Bolstad BM, Collin F, Cope LM, Hobbs B, Speed TP: Summaries of Affymetrix GeneChip probe level data. Nucleic Acids Res 2003, 3 I(4): el5.

30. Subramanian A, Tamayo P, Mootha VK, Mukherjee S, Ebert BL, Gillette MA, Paulovich A, Pomeroy SL, Golub TR, Lander ES, Mesirov JP: Gene set enrichment analysis: a knowledge-based approach for interpreting genome-wide expression profiles. Proc Natl Acad Sci U S A 2005, I 02(43): I5545-I5550.

3I. Graef IA, Chen F, Crabtree GR: NFAT signaling in vertebrate development. Curr Opin Genet Dev 200I, II (5):505-5I 2.

32. de la Pompa JL, Timmerman LA, Takimoto H, Yoshida H, Elia AJ, Samper E, Potter J, Wakeham A, Marengere L, Langille BL, Crabtree GR, 
Mak TW: Role of the NF-ATc transcription factor in morphogenesis of cardiac valves and septum. Nature 1998, 392(6672): $182-186$.

33. Arron JR, Winslow MM, Polleri A, Chang CP, Wu H, Gao X, Neilson JR, Chen L, Heit JJ, Kim SK, Yamasaki N, Miyakawa T, Francke U, Graef IA, Crabtree GR: NFAT dysregulation by increased dosage of DSCRI and DYRKIA on chromosome 2I. Nature 2006, 44 I (7093):595-600.

34. Dowjat WK, Adayev T, Kuchna I, Nowicki K, Palminiello S, Hwang YW, Wegiel J: Trisomy-driven overexpression of DYRKIA kinase in the brain of subjects with Down syndrome. Neurosci Lett 2006.

35. Cheon MS, Shim KS, Kim SH, Hara A, Lubec G: Protein levels of genes encoded on chromosome $2 I$ in fetal Down syndrome brain: Challenging the gene dosage effect hypothesis (Part IV). Amino Acids 2003, 25(I):4l-47.

36. Greber-Platzer S, Schatzmann-Turhani D, Wollenek G, Lubec G: Evidence against the current hypothesis of "gene dosage effects" of trisomy 21 : ets-2, encoded on chromosome 21 "is not overexpressed in hearts of patients with Down Syndrome. Biochem Biophys Res Commun 1999, 254(2):395-399.

37. Reeves RH, Baxter LL, Richtsmeier JT: Too much of a good thing: mechanisms of gene action in Down syndrome. Trends Genet 200I, I 7(2):83-88.

38. Kim SH, Vlkolinsky R, Cairns N, Lubec G: Decreased levels of complex III core protein I and complex $V$ beta chain in brains from patients with Alzheimer's disease and Down syndrome. Cell Mol Life Sci 2000, 57(12):1810-1816.

39. Kim SH, Vlkolinsky R, Cairns N, Fountoulakis M, Lubec G: The reduction of NADH ubiquinone oxidoreductase 24- and 75 kDa subunits in brains of patients with Down syndrome and Alzheimer's disease. Life Sci 200I, 68(24):274I-2750.

40. Prince J, Jia S, Bave U, Anneren G, Oreland L: Mitochondrial enzyme deficiencies in Down's syndrome. J Neural Transm Park Dis Dement Sect 1994, 8(3): |7|-|8I.

41. Wright TC, Orkin RW, Destrempes M, Kurnit DM: Increased adhesiveness of Down syndrome fetal fibroblasts in vitro. Proc Natl Acad Sci U S A 1984, 8 I(8):2426-2430.

42. Kurnit DM, Aldridge JF, Neve RL, Matthysse S: Genetics of congenital heart malformations: a stochastic model. Ann N Y Acad Sci 1985, 450:191-204.

43. Kurnit DM, Aldridge JF, Matsuoka R, Matthysse S: Increased adhesiveness of trisomy $2 \mathrm{I}$ cells and atrioventricular canal malformations in Down syndrome: a stochastic model. $\mathrm{Am} \mathrm{J} \mathrm{Med}$ Genet 1985, 20(2):385-399.

44. Gittenberger-de Groot AC, Bartram U, Oosthoek PW, Bartelings MM, Hogers B, Poelmann RE, Jongewaard IN, Klewer SE: Collagen type VI expression during cardiac development and in human fetuses with trisomy 2I. Anat Rec A Discov Mol Cell Evol Biol 2003, 275(2): I 109-I I I6.

45. Cai DH, Vollberg TM Sr., Hahn-Dantona E, Quigley JP, Brauer PR: MMP-2 expression during early avian cardiac and neural crest morphogenesis. Anat $\operatorname{Rec} 2000,259(2): 168-179$.

46. Person AD, Klewer SE, Runyan RB: Cell biology of cardiac cushion development. Int Rev Cytol 2005, 243:287-335.

47. Sharma HS, Peters TH, Moorhouse MJ, van der Spek PJ, Bogers AJ: DNA microarray analysis for human congenital heart disease. Cell Biochem Biophys 2006, 44(I): I-9.

48. Lange AW, Rothermel BA, Yutzey KE: Restoration of DSCRI to disomy in the trisomy 16 mouse model of Down syndrome does not correct cardiac or craniofacial development anomalies. Dev Dyn 2005, 233(3):954-963.

49. Fuentes JJ, Genesca L, Kingsbury TJ, Cunningham KW, Perez-Riba M, Estivill X, de la Luna S: DSCRI, overexpressed in Down syndrome, is an inhibitor of calcineurin-mediated signaling pathways. Hum Mol Genet 2000, 9(I I): 168I-1690.

50. Qin L, Zhao D, Liu X, Nagy JA, Hoang MV, Brown LF, Dvorak HF, Zeng H: Down Syndrome Candidate Region I Isoform I Mediates Angiogenesis through the Calcineurin-NFAT Pathway. Mol Cancer Res 2006, 4( I I):8 I I-820.

5I. Bushdid PB, Osinska H, Waclaw RR, Molkentin JD, Yutzey KE: NFAT 33 and NFAT 44 are required for cardiac development and mitochondrial function. Circ Res 2003, 92(I 2): | 305- I3 | 3

52. Askanas V, McFerrin J, Baque S, Alvarez RB, Sarkozi E, Engel WK: Transfer of beta-amyloid precursor protein gene using adenovirus vector causes mitochondrial abnormalities in cul- tured normal human muscle. Proc Natl Acad Sci U S A 1996 93(3): $|3| 4-1319$

53. Vogel W, Gish GD, Alves F, Pawson T: The discoidin domain receptor tyrosine kinases are activated by collagen. Mol Cell 1997, I(I): I3-23

54. Vogel WF, Aszodi A, Alves F, Pawson T: Discoidin domain receptor I tyrosine kinase has an essential role in mammary gland development. Mol Cell Biol 200I, 2 I (8):2906-29I7.

55. Faraci E, Eck M, Gerstmayer B, Bosio A, Vogel WF: An extracellular matrix-specific microarray allowed the identification of target genes downstream of discoidin domain receptors. Matrix Biol 2003, 22(4):373-38I.

56. Morales MO, Price RL, Goldsmith EC: Expression of Discoidin Domain Receptor 2 (DDR2) in the developing heart. Microsc Microanal 2005, I I (3):260-267.

57. Dermitzakis ET, Reymond A, Scamuffa N, Ucla C, Kirkness E, Rossier $\mathrm{C}$, Antonarakis SE: Evolutionary discrimination of mammalian conserved non-genic sequences (CNGs). Science 2003, 302(5647): $1033-1035$.

58. Affymetrix Homepage [http://www.affymetrix.com/index.affx]

59. Gene Expression Omnibus [http://www.ncbi.nlm.nih.gov/ projects/geo/]

60. Wu Z, Irizarry RA: Preprocessing of oligonucleotide array data. Nat Biotechnol 2004, 22(6):656-8; author reply 658.

6I. Jornsten R, Yu B: Simultaneous gene clustering and subset selection for sample classification via MDL. Bioinformatics 2003, I 9(9): I 100-I I09.

62. Bassett DE Jr., Eisen MB, Boguski MS: Gene expression informatics--it's all in your mine. Nat Genet 1999, 2 I ( I Suppl):5 I-55.

63. Zhang B, Schmoyer D, Kirov S, Snoddy J: GOTree Machine (GOTM): a web-based platform for interpreting sets of interesting genes using Gene Ontology hierarchies. BMC Bioinformatics 2004, 5: 16 .

64. Gene Ontology Tree Machine [http://bioinfo.vanderbilt.edu/ gotm/]

65. Pandey R, Guru RK, Mount DW: Pathway Miner: extracting gene association networks from molecular pathways for predicting the biological significance of gene expression microarray data. Bioinformatics 2004, 20(13):2156-2I 58.

66. Bio Resource for Array Genes [http://www.biorag.org/]

67. Gene Set Enrichment Analysis: Overview [http:// www.broad.mit.edu/gsea/]

68. Bio-Rad [http://www.bio-rad.com]

69. Primer 3 Software [http://frodo.wi.mit.edu/cgi-bin/primer3/ primer3 www.cgi/]
Publish with Biomed Central and every scientist can read your work free of charge

"BioMed Central will be the most significant development for disseminating the results of biomedical research in our lifetime. "

Sir Paul Nurse, Cancer Research UK

Your research papers will be:

- available free of charge to the entire biomedical community

- peer reviewed and published immediately upon acceptance

- cited in PubMed and archived on PubMed Central

- yours - you keep the copyright
BioMedcentral 